\title{
A Systematic Study of Shear-Tolerant Micro-Emulsion Fracturing Fluid
}

\section{Lecheng Zhang ${ }^{1,2}$, Zhengdong Cheng ${ }^{1-4 \star}$, Lijuan $\operatorname{Han}^{5}$, Xu Wang ${ }^{6}$, Fuchen Liu ${ }^{6}$, Xianwen $\mathrm{Li}^{7}$ and Minxiang Zeng}

${ }^{1}$ Artie McFerrin Department of Chemical Engineering, Texas AEM University, College Station, TX 77843-3122, USA

${ }^{2}$ Mary Kay O'Connor Process Safety Center, Artie McFerrin Department of Chemical Engineering, Texas AEM University, College Station, TX 77843-3122, USA

${ }^{3}$ Materials Science and Engineering, Texas AEM University, College Station, TX 77843-3003, USA

${ }^{4}$ Professional Program in Biotechnology, Texas AEM University, College Station, TX 77843-3122, USA

${ }^{5}$ State Key Laboratory of Oil and Gas Reservoir Geology and Exploitation, Southwest Petroleum University, Chengdu 610500, Sichuan, P. R. China

${ }^{6}$ CNPC USA Corporation, Houston, TX 77042, USA

${ }^{7}$ Changqing Oilfield Company, PetroChina, Xi'an 710018, Shanxi Province, P. R. China

Article Info

\section{*Corresponding author: \\ Zhengdong Cheng}

Artie McFerrin Department of Chemical

Engineering

Texas A\&M University

College Station

TX 77843-3122, USA

E-mail: zcheng@tamu.edu

Received: March 20, 2017

Accepted: April 6, 2017

Published: April 12, 2017

Citation: Zhang L, Cheng Z, Han L, et al. A Systematic Study of Shear-Tolerant MicroEmulsion Fracturing Fluid. Int J Petrochem Res. 2017; 1(1): 26-30.

doi: 10.18689/ijpr-1000106

Copyright: @ $₫ 2017$ The Author(s). This work is licensed under a Creative Commons Attribution 4.0 International License, which permits unrestricted use, distribution, and reproduction in any medium, provided the original work is properly cited.

Published by Madridge Publishers

\begin{abstract}
Fluid loss control, formation damage prevention and mitigation are critical issues that affect hydraulic fracturing productivity in the low permeability gas reservoirs. In this work, we propose that micro-emulsion fracturing fluids should be used to reduce fluid loss and avoid formation damage. We used the Winsor IV single phase micro-emulsions, emulsified by non-ionic surfactants and co-surfactants, as emulsion component. Then, we mixed the emulsion with Guar Gum component, formulated a micro-emulsion fracturing fluid. Different parameters of formulated system, including gelation times, shearing tolerance at high temperature, fluid loss, formation damage and pipe friction were evaluated to characterize this novel fracturing fluid. With comprehensive measurements and evaluations, along with comparison to the conventional fracturing fluids, we have demonstrated that the micro-emulsion fracturing fluid has less fluid loss, controllable formation damage, and it can still maintain a high viscosity under high temperature for a long period. The proposed micro-emulsion fracturing fluids have the potential to solve fluid loss and formation damage problems which are affecting fracturing treatment for the high temperature and low permeability formations.
\end{abstract}

Keywords: Hydraulic fracturing, Micro-emulsions, Fluid loss, Formation damage, Sheartolerant

\section{Introduction}

Undoubtedly, hydraulic fracturing technique and horizontal drilling techniques have changed the landscape of the world's energy production. Successful applications of hydraulic fracturing technique on the unconventional shale gas formations leveraged world energy production, especially for North America area, meanwhile creating thousands of jobs. However, innovations for fracturing operations are still demanded to reduce cost, increase well life span and secure energy supply for centuries.

Fluid loss and formation damage are two factors limiting fracturing operations since it was developed [1]. The primary concern for a fracturing treatment is fluid loss. Fluid loss issues increase the total water consumption for fracturing treatment, which puts 
hydraulic fracturing under controversy and also increases cost of fracturing operation. The second problem, formation damage, reduces formation permeability, which limits well lifetime and undermines productivity.

Several new technologies have been proposed to solve these problems, such as critical state $\mathrm{CO}_{2}$ or liquefied petroleum gas (LPG) [2] [3]. One drawback of such techniques is that they are utterly different from the conventional fracturing process, thus costing more to modify the current equipments. ViscoElastic Surfactants (VES) fracture [4] [5] is another new technology developed to solve fluid loss problem. However, under high temperature and high shear rate conditions, fluid viscosity would be compromised, besides the high cost of VES.

Micro-emulsions, which have already been widely applied in upstream, are mixtures of oil and water with surfactants [6] [7] [8]. Applications of micro-emulsions/gel as fracturing fluids were reported by other groups [9] [10] [11]. By altering wettability of pore throat, micro-emulsion can hydrophobize rock surface and reduce capillary pressure. A lower capillary pressure is preferred in many ways, from increasing productivity to reducing trapped fluid phase. In addition, benefited from the fact that micro-emulsion fracturing fluids are still homogeneous liquid phase under ambient temperature and pressure, instruments for conventional fluids can also implement micro-emulsion fracturing fluids with minor changes, which avoids cost for new treatment systems. Last but not least, micro-emulsion has a higher surface volume ratio compared to macro-emulsion system. By virtue of large surface volume ratio, emulsion droplets have higher chance to contact with rock surface hence alter the wettability. Also diesel usage in the fluids is reduced by the large surface volume ratio, which renders the diesel fracturing fluid as an economy method for fracturing.

Here we present a systematic investigation on the application of micro-emulsion based fracturing fluids to reduce fluid loss and formation damage, aiming to provide other researchers a standard protocol to test different microemulsion fracturing fluid systems. To obtain a stable emulsion, we screened different compositions of water, oil and surfactants. With the aid of a ternary phase diagram (Figure 1), we located the stable Winsor IV phase micro-emulsions. Based on that, we developed micro-emulsion fracturing fluids. Fluid rheology is the most crucial parameters for fracturing fluids [12]. In our work, fluid rheological properties were measured and formation damage was evaluated with synthetic core samples. Experiment results showed that the new micro-fracturing fluids can maintain a high viscosity under high shearing rate and high temperature. Further investigations on microemulsion fracturing system also showed a reduced formation damage and fluid loss.

\section{Materials and Methods}

Triton-X $100 \quad$ (4-(1,1,3,3-Tetramethylbutyl)phenylpolyethylene glycol, Surfactant), Ammonium persulfate (Breaker) and n-butanol (Co-surfactant) are purchased from Sigma-Aldrich. Hydroxypropyl Guar Gum (HPGG,Viscosifier), organoboron crosslinker HYJ-2 are purchased from Shuntong Chemical, China. Encapsulated breaker OB-1 is obtained from Southwest Petroleum University, China. Diesel component is directly purchased from market (Shell, United States).

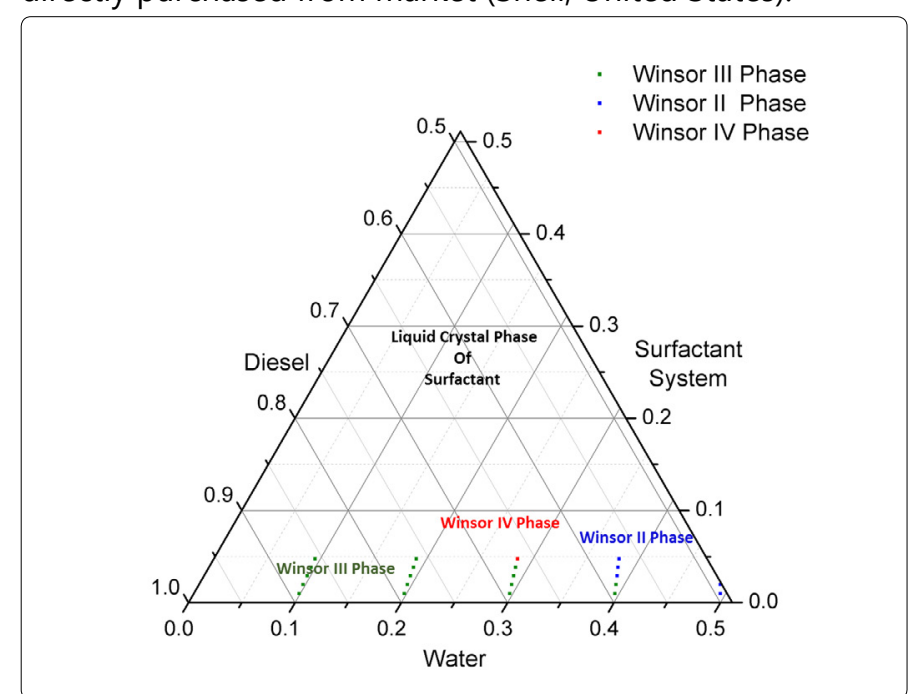

Figure 1. A tertiary phase diagram of Triton-X 100/n-Butanol,

Diesel, Water mixture (zoomed into the Diesel corner). Compositions are labeled in weight ratio. Different color indicates the different Winsor phase type, see legend. Winsor II, III, IV phases were observed. The formulation of micro-emulsion fracturingfluids is based on the composition of Winsor IV emulsions.

We used diesel as a model oil phase to explore the phase behaviors of the micro-emulsion fracturing fluids. Blended surfactant serving as an emulsifier was obtained by mixing primary surfactant Triton-X 100 with co-surfactant n-Butanol under magnetic stirring with 2:1 mass ratio. The mixture was then stocked for later use. A thorough phase behavior study was carried out to locate an optimal composition for the micro-emulsion fracturing fluids. Results are shown in Figure 1 and Figure 2. Phase diagram (Figure 1) is drafted according the emulsion phase behaviors under different compositions. Formula for the single phase micro-emulsion (Winsor IV in Figure $2 e$ and red symbol in Figure 1) can be obtained by mixing emulsifier, diesel and water in a 0.5:69.65: 29.85 weight ratio. The micro-emulsions are thermodynamically equilibrate phase and very stable. A batch of 6 -months old samples were compared with fresh samples shown in Figure 2 and barely changed. Micro-emulsion forms spontaneously and requires minimal external energy input. A uniform single phase microemulsion can be simply acquired by shaking the sample vials manually. Emulsion size and droplet morphology were also checked by microscope (Figure 3. Insert) 


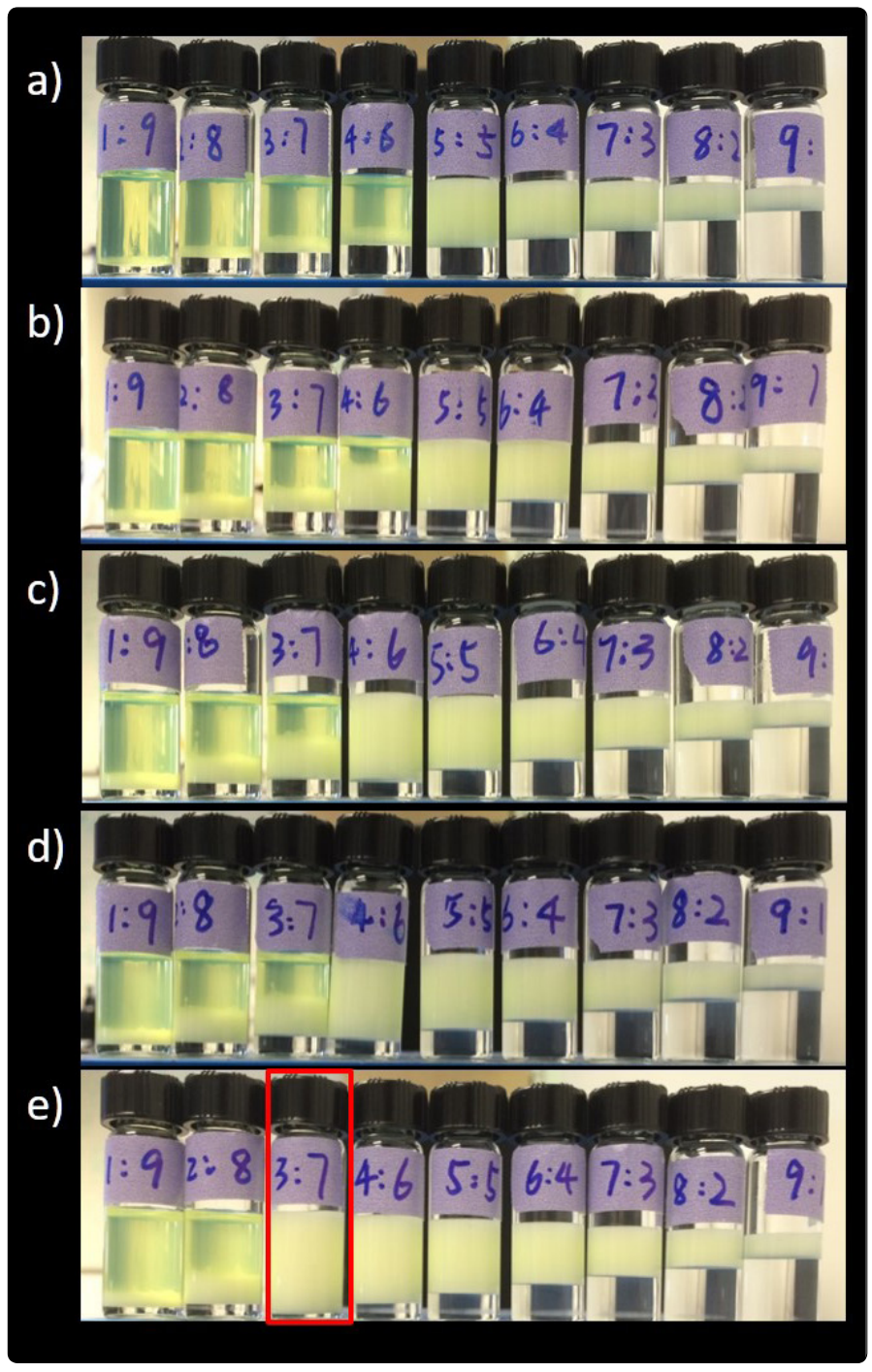

Figure 2. Phase behaviour scanning. From left to right, the oil to water ratio descends as labeled on the vials. Surfactant concentrations were $0.1 \%, 0.2 \%, 0.3 \%, 0.4 \%, 0.5 \%$ for row $a), b), c$ ), d), e), respectively. Pictures were taken after samples had been set still for 1 week. A Winsor IV type emulsion (marked as red in picture) was chosen to make the fracturing fluids.

A gel based fracturing fluid was formulated according to the formula mentioned as following. The gel based fracturing fluid consists of 2000-6000mg/L Hydroxypropyl Guar Gum (HPGG), 2000-10000 mg/L organo boron crosslinker, 1000$10000 \mathrm{mg} / \mathrm{L}$ breaker (ammonium persulfate) and 500-1000 $\mathrm{mg} / \mathrm{L}$ high temperature stabilizer (alkyl alkanolamine). Within these compositions, the fracturing fluid can quickly form a gel at 40 to $100^{\circ} \mathrm{C}$ by vigorous mixing. Gel quality was checked visually before next step. Then the single phase micro emulsions were mixed with the gel based fracturing fluid in a 1:9 weight ratio and used for all later tests.

Interfacial tension (IFT) between the diesel oil phase and aqueous phase under influence of blended surfactants was measured with spinning drop method (M6500 Spinning Drop Tensiometer, Grace Instrument ${ }^{\circledR}$ ). The IFT profile shows in Figure 3 that Triton-X/n-Butanol reaches its critical micelle concentration at $0.2 \mathrm{w} / \mathrm{w} \%$ surfactant concentration, which was consistent with emulsion phase study results shown in Figure 1 and Figure 2.

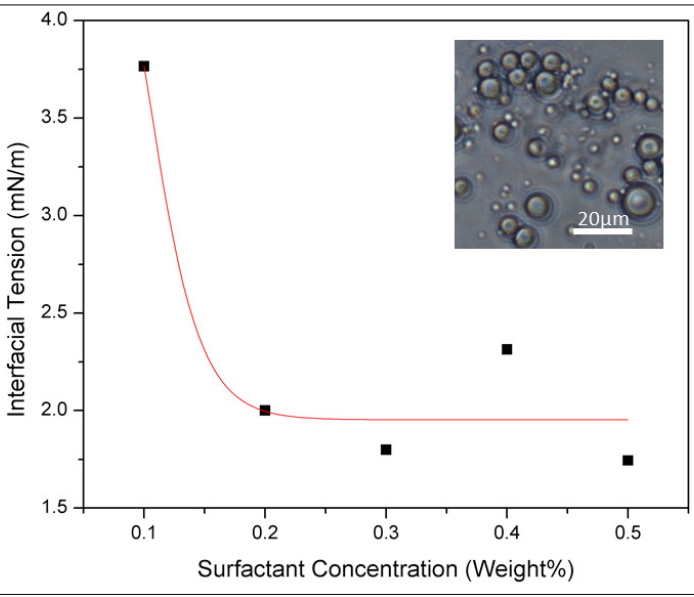

Figure 3. Interfacial tension between the diesel oil and water interface with different concentrations of surfactants. The red line represents the fitted result with lognormal model. Four data points

from right side, $0.2 \%, 0.3 \%, 0.4 \%, 0.5 \%$, respectively, showed

interfatial tension reached a pleateu. Thus we conclude the concentration of surfactant already reached their critical micelle concentration (CMC). Insert is microscopic image of micro-emulsion with $3: 7$ oil to water ratio and 0.5 w.t. \% surfactant.

\section{Result and Discussion}

\section{Rheological Characterization}

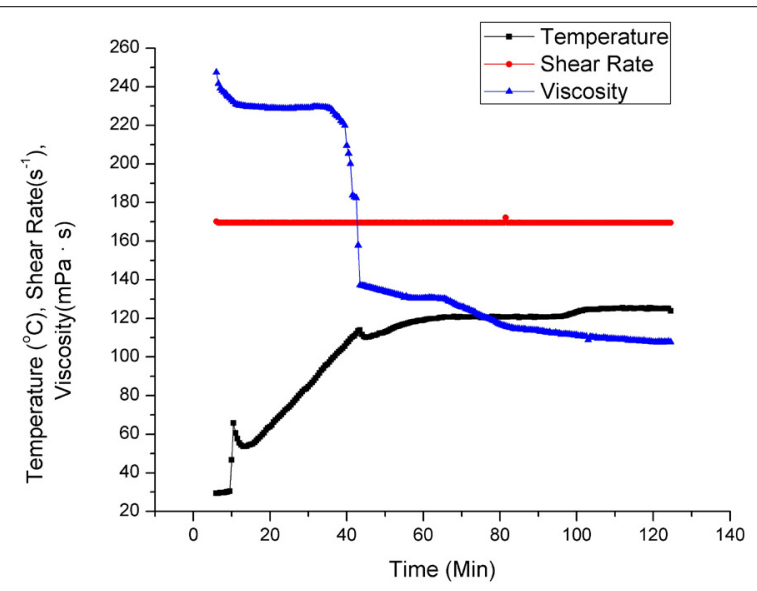

Figure 4. Rheological change of the micro-emulsion fracturing fluidunder $120^{\circ} \mathrm{C}$ and $170 \mathrm{~s}^{-1}$ shearing rate.

Rheological property is tested with rheometer (HAAKE Rheo Stress 600). To represent the real shearing force induced by underground formation, the shear rate is set at $170 \mathrm{~s}^{-1}$. Meanwhile, we introduced a gradual temperature increase to simulate the temperature increase caused by tube friction. As shown in Figure 4, fracturing fluid was sheared under a $170 \mathrm{~s}^{-1}$ shearing rate and temperature was gradually increased to $120^{\circ} \mathrm{C}$ at $5^{\circ} \mathrm{C} / \mathrm{min}$ increasing rate. Due to initial temperature ramping, viscosity decreased, but after temperature reached plateau, fluid system can maintain a viscosity above $100 \mathrm{mPa} \cdot S$ for more than 2 hours. This result demonstrate that our microemulsion fracturing fluid exhibits an excellent shear-tolerant property under high temperature.

\section{Fluid Loss Measurement}

To evaluate the fluid loss, we compared the microemulsion fracturing and conventional fracturing system and 
measured leakoffs of different fracturing fluid systems with different micro-emulsion percentages. A lab-built leakoff measuring system is used and experiments are conducted under following conditions. Synthetic 500 PSI (3.5 MPa) differential pressure is applied on the two sides of filtration cell. Then, volume of fluid that flows out is measured with cylinder. Temperature was controlled at $90^{\circ} \mathrm{C}$ during the tests. Applied pressure lasted 36 minutes during the test. Experiment results were plotted in Figure 5. The synthetic core samples used in these tests were manufactured according to the composition of Sulige Eastern formation.

Result showed that a concentration of $5 \%$ or above of micro-emulsion can significantly reduce fluid loss. Although the change between $5 \%$ and $10 \%$ was subtle, we decide to use $10 \%$ concentration of micro-emulsions in our research for better demonstrations.

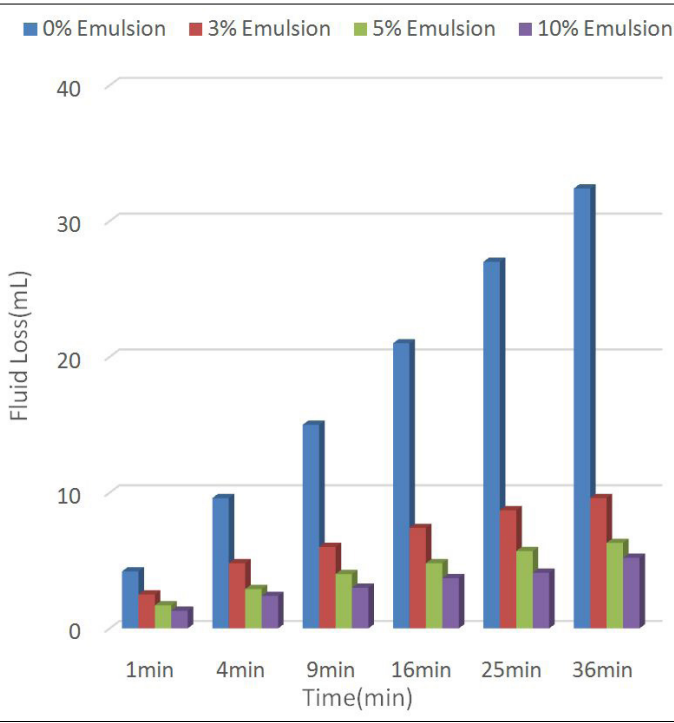

Figure 5. Fluid loss for different fracturing fluid fomulas with different micro-emulsion percentages.

\section{Formation Damage Test}

The core permeability can be calculated with DarcyWeisbach equation,

$$
K=\frac{Q \cdot \mu \cdot L}{\Delta P \cdot A}
$$

Where $\mathrm{K}$ is sample permeability, $\mu \mathrm{m}^{2}, \mathrm{Q}$ is flow rate, $\mathrm{ml} / \mathrm{s}$, $L$ is core sample length, $\mathrm{cm}, A$ is core sectional area, $\mathrm{cm}^{2}, \Delta P$ is pressure difference, $\mathrm{MPa}$, and $\mathrm{M}$ is fluid viscosity, $\mathrm{mPa} \cdot \mathrm{s}$.

Formation damage can be characterize by the percentage of permeability reduction:

$$
\eta=\frac{K_{1}-K_{2}}{K_{1}} \times 100 \%
$$

Where $K_{1}$ is the permeability before fracturing fluid flooding, and $K_{2}$ is the permeability after fracturing fluid flooding.

Experiments were conducted under $120^{\circ} \mathrm{C}$ with core flooding setup, as shown in Table 1. Data showed that the conventional guar gel fracturing fluid decreases formation permeability by $57.9 \%$, however, our micro-emulsion fracturing fluid only decreases permeability by $16.4 \%$. Hence we conclude that micro-emulsion fracturing fluids only causes marginal changes in permeability compared to the conventional guar gel fracturing fluid.

Table 1. Formation Damage Test Data

\begin{tabular}{|c|c|c|c|c|c|c|c|}
\hline Type & $\begin{array}{c}\text { Core } \\
\text { Sample } \\
\text { No. }\end{array}$ & $\begin{array}{c}\text { Length } \\
(\mathrm{cm})\end{array}$ & $\begin{array}{c}\text { Diameter } \\
(\mathrm{cm})\end{array}$ & $\begin{array}{c}\text { Porosity } \\
(\%)\end{array}$ & $\begin{array}{c}\text { Permeability } \\
\text { before test } \\
\left(\mu \mathrm{m}^{2}\right)\end{array}$ & $\begin{array}{c}\text { Permeability } \\
\text { after test } \\
\left(\mu \mathrm{m}^{2}\right)\end{array}$ & $\begin{array}{c}\text { Formation } \\
\text { damage\% }\end{array}$ \\
\hline $\begin{array}{c}\text { Guar } \\
\text { GelFrac }\end{array}$ & $1 \#$ & 4.91 & 2.54 & 14.59 & $1.469 \times 10^{0-3}$ & $0.619 \times 10^{-3}$ & 57.9 \\
\hline $\begin{array}{c}\text { Micro- } \\
\text { Emulsion } \\
\text { Frac }\end{array}$ & $2 \#$ & 5.73 & 2.54 & 14.6 & $2.647 \times 10^{-3}$ & $2.212 \times 10^{-3}$ & 16.4 \\
\hline
\end{tabular}

\section{Tube Friction Test}

Tube friction test was carried out by a coiled tubing system with $0.001 \mathrm{kPa}$ pressure resolution. The total length of the coil was 3 meters. We used two different inner diameter tubes, $0.46 \mathrm{~cm}$ and $1.01 \mathrm{~cm}$, respectively, and each test last 2 hours. The micro-emulsion fracturing fluids formulated according to previous paragraph were then injected. Also we tested the fluids under two different temperatures, $40^{\circ} \mathrm{C}$ and $80^{\circ} \mathrm{C}$, respectively. Results showed in Figure 6 . The purpose of these experiments is to provide friction reference data for later field applications.
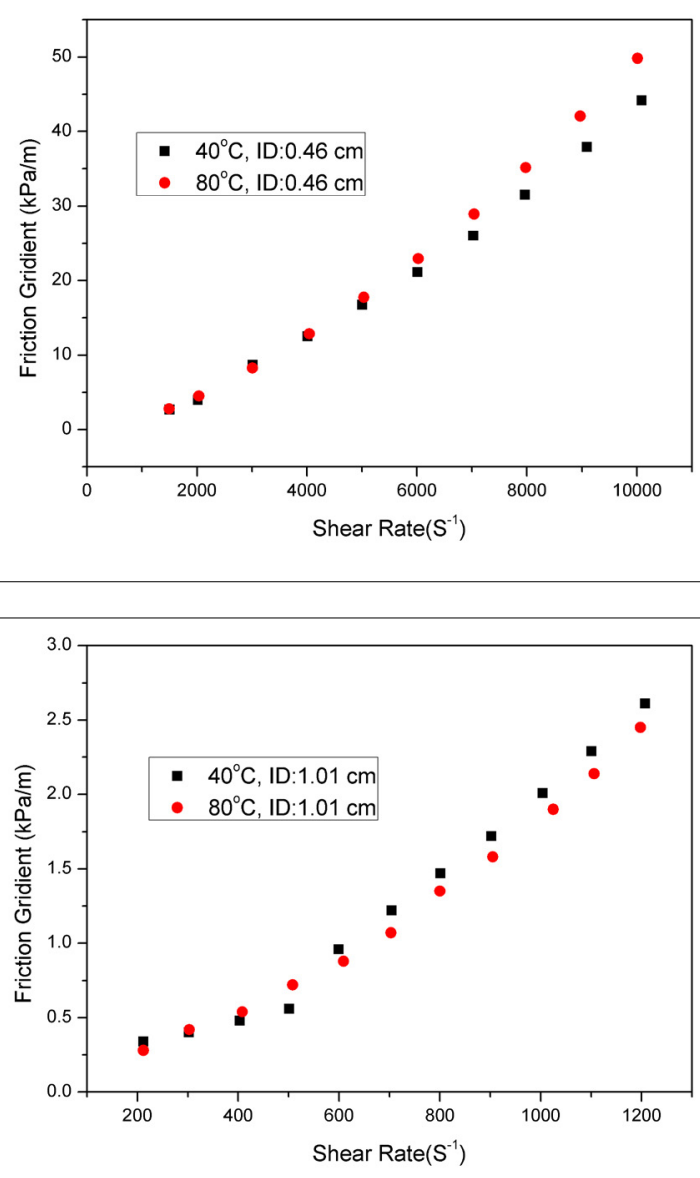

Figure 6. Tube friction profiles with $0.46 \mathrm{~cm}, 1.01 \mathrm{~cm}$ tubings, under $40^{\circ} \mathrm{C}$ and $80^{\circ} \mathrm{C}$.

\section{Compatible Breaker Systems}

The gel breaking time can be controlled by adding different amount of breakers. Depending on the amount of breaker, it usually takes 60 to 120 minutes for the breaking 
process to complete. Two different breaking chemicals are tested, namely, ammonium persulfate and encapsulated breaker. Both chemicals are compatible with our fracturing system and the breaking times for different chemicals are similar.

\section{Conclusion}

To solve the fluid loss and formation damage problems during fracturing operations, we developed a micro-emulsion based fracturing fluids. The ternary phase diagram was used to locate the optimal composition of the fracturing fluids. Afteroptimizing fluid composition, rheological characterization was measured to access the fluid shear tolerance. Fluid loss and formation damage tests were also carried out to evaluate the fracturing fluids. Results showed that our micro-emulsion fracturing fluids have a robust shear resistance, which ensures a high operation fluid viscosity after pumping down fluid into formation. In addition, our micro-emulsion fracturing fluids caused less fluid loss and formation damage comparing to conventional guar gum fracturing fluids. Compatible breaker system was suggested here for consideration in field implementation. Tube friction profile was measured to provide a reference for field applications. The intrinsic properties of micro-emulsions and micro-emulsion fracturing fluids make them promising tools for economy fracturing operation with increased production lifetime. Also, this comprehensive research work on micro-emulsion fracturing fluid explored a standardized protocols for the later research.

\section{Nomenclature}

Visco-Elastic surfactant (VES)

Liquefied petroleum gas (LPG)

Hydroxypropyl Guar Gum (HPGG)

Interfacial tension (IFT)

\section{Acknowledgments}

We would like to thank Mr. Xiaoda Liu for helpful discussion. The experiments were carried out under research program C3570 under Texas A\&M Engineering Experiment Station (TEES).

\section{References}

1. Penny GS, Pursley JT, Holcomb D.The application of microemulsion additives in drilling and stimulation results in enhanced gas production. SPE Production Operations Symposium. Society of Petroleum Engineers. 2005.

2. Tudor EH, Nevison GW, Allen S, Pike B. $100 \%$ gelled LPG fracturing process: an alternative to conventional water-based fracturing techniques. SPE Eastern Regional Meeting. Society of Petroleum Engineers. 2009.

3. Grassman D, Zingg W. Well fracturing method using liquefied gas as fracturing fluid: Google Patents, 1974.

4. Samuel MM, Card RJ, Nelson EB, et al. Polymer-free fluid for fracturing applications. Spe Drill Completion. 1999; 14(4): 240-46. doi: 10.2118/59478-PA

5. Deng Q, Xu JF, Gu XF, Tang Y. Properties Evaluation of Polymer-free Fluid for Fracturing Application. Adv Mater Res-Switz. 2012; 482-484: 1180-83.

6. Pursley JT, Penny G, Holcomb D. Microemulsion additives enable optimized formation damage repair and prevention. SPE International Symposium and Exhibition on Formation Damage Control. Society of Petroleum Engineers. 2004.

7. Kim J, Gomaa AM, Nelson SG, Hudson HG. Engineering Hydraulic Fracturing Chemical Treatment to Minimize Water Blocks: A Simulated Reservoir-on-a-Chip Approach. SPE International Conference and Exhibition on Formation Damage Control. Society of Petroleum Engineers. 2016.

8. Bui K, Akkutlu IY, Zelenev A, Saboowala H, Gillis JR, Silas JA. Insights Into Mobilization of Shale Oil by Use of Microemulsion. SPE J. 2016; 21(2): 1-8.

9. Liu DX, Fan MF, Yao LT, Zhao XT, Wang YL. A new fracturing fluid with combination of single phase microemulsion and gelable polymer system. J Petrol Sci Eng. 2010; 73(3-4): 267-71. doi: 10.1016/j. petrol.2010.07.008

10. He K, Xu L, Gao YF, Yin XL, Neeves KB. Evaluation of surfactant performance in fracturing fluids for enhanced well productivity in unconventional reservoirs using Rock-on-a-Chip approach. J Petrol Sci Eng. 2015; 135: 531-41. doi: 10.1016/j.petrol.2015.10.008

11. Penny GS, Dobkins TA, Pursley JT. Field study of completion fluids to enhance gas production in the Barnett Shale. SPE gas technology symposium. Society of Petroleum Engineers. 2006.

12. Dantas TNC, Santanna VC, Neto AAD, Neto ELB, Moura MCPA Rheological properties of a new surfactant-based fracturing gel. Colloid Surface A. 2003; 225(1-3): 129-35. doi: 10.1016/S0927-7757(03)00355-8. 